Original Research Paper

\title{
Effect of Deploying the Flow Guide Vane in Upstream of Triangular Duckbill Weirs on the Efficiency of this Type of Weir in Laboratory Conditions
}

\author{
${ }^{1}$ Sayedeh Zahra Hosseini-Teshnizi, ${ }^{1}$ Manuchehr Heidarpour, ${ }^{1}$ Saeid Eslamian, \\ ${ }^{2}$ Vijay P. Singh and ${ }^{3}$ Kaveh Ostad-Ali-Askari \\ ${ }^{I}$ Department of Water Engineering, College of Agriculture, Isfahan University of Technology, Isfahan, Iran \\ ${ }^{2}$ Department of Biological and Agricultural Engineering and Zachry Department of Civil Engineering, \\ Texas A and M University, 321 Scoates Hall, 2117 TAMU, College Station, Texas 77843-2117, U.S.A \\ ${ }^{3}$ Department of Civil Engineering, Isfahan (Khorasgan) Branch, Islamic Azad University, Isfahan, Iran
}

\section{Article history}

Received: 27-09-2018

Revised: 23-11-2018

Accepted: 26-06-2019

Corresponding Author: Sayedeh Zahra HosseiniTeshnizi

Department of Water Engineering, College of Agriculture, Isfahan University of Technology, Isfahan, Iran Emails: sz.hosseiniteshnizi@ag.iut.ac.ir zahrahosseini_irri@yahoo.com

\begin{abstract}
One of the effective ways for the flow of water in low head water conditions is using triangular duckbill weirs. Regarding the high efficiency of these weirs in higher rate of flow discharge in constant head water conditions, the investigation about this type of weirs is greatly required. The present study is done on triangular duckbill weir with two different vertex angle, installed in the laboratory straight channel. In the upstream of the installation place of the triangular duckbill weir, some flow guide vanes with different specifications are installed and the required tests were done in three different groups. The discharge coefficient was calculated by obtaining the required laboratory parameters, such as upstream water level and upstream velocity in free flow conditions. The ration of the flow discharge over triangular duckbill weir to the flow discharge of straight weir was calculated and the graphs relative to the total water head were drawn. The results show that the flow guide vane with smaller width has more effects on the efficiency of the triangular duckbill weir. Moreover, in all wall angle of located vane, the efficiency of weir with larger vertex angle is less than that with smaller vertex angle. Since the flow interference is increased by increasing the flow discharge in the triangular duckbill weir with low vertex angle, then, the presence of the flow guide vanes can reduce the horizontal component and increase the vertical component of upstream velocity over the weir. Thus, the flow passes with more velocity over the weir crest at the same time and the flow discharge rate is increased and therefore the efficiency of this weir is increased.
\end{abstract}

Keywords: Straight Channel, Flow Guide Vane, Vertical Component of the Velocity, Discharge Coefficient, Effective Length of the Crest

\section{Introduction}

Weirs are used to control the water level and measuring flow in different forms. One of the effective and economical ways to increase the effective length of the crest is using labyrinth weirs. These weirs that have been considered in recent years are called by different names, such as duckbill, corrugated and labyrinth weirs. Generally, these weirs are defined by broken axis that are in trapezoid, triangular, rectangular, or Ushape forms and can be repeated in few cycles. The weir axis is in the form of a broken line, causing the effective length of its crest to be more as compared to a straight line crests (Abrishami and Hosseini, 1993). According to Fig. 1, it can be seen that in contrast to straight weirs, the flow direction over these weirs is not perpendicular to the crest edge and passing with an oblique angle over the crest. In upstream and downstream areas, the flow direction is mainly parallel to the symmetrical axis of the weir and not perpendicular to the weir crest and this phenomenon is observed more in the downstream areas that the flow is accumulated and overflown. This causes to reduce the weir efficiency (Hay and Taylor, 1970). 


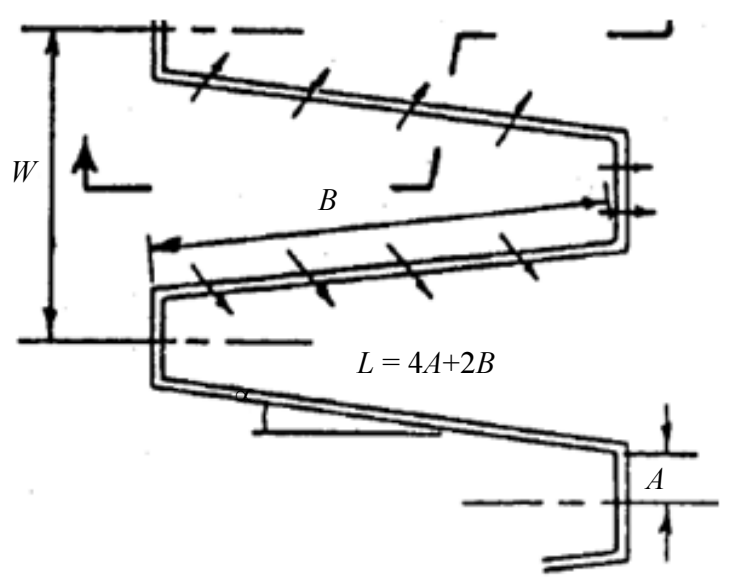

Fig. 1: Sketch of flow over the triangular duckbill weir

The flow over the weir with sharp edge in a free flow in a channel follows Equation 1:

$$
Q=\frac{2}{3} \times C_{d} \sqrt{2 g} \times L H t^{3 / 2}
$$

where, $Q$ is the discharge flow $\left(\mathrm{m}^{3} / \mathrm{s}\right), g$ is the gravitational acceleration $\left(9.81 \mathrm{~m} / \mathrm{s}^{2}\right), L$ is the effective length of the weir $(\mathrm{m}), H_{t}$ is the total head water (m) including the upstream head water on the weir added with the dynamic head $\left(V^{2} / 2 g-V\right.$ is the average upstream velocity in $\mathrm{m} / \mathrm{s}$ ) and $C_{d}$ is the discharge coefficient.

The first attempt to analyze the efficiency of duckbill weirs can be attributed to Taylor. By analyzing these weirs, he concluded that duckbill weirs have higher coefficients than the straight weirs in a channel with similar width (Tullis et al., 1995). Hay and Taylor (1970) analyzed the efficiency of duckbill weirs with triangular and trapezoidal plans relative to the sharp edge straight weirs. They found out that the efficiency of duckbill weirs with triangular plans is more appropriate than that with trapezoidal plans. Hay and Taylor (1970) and Tullis et al. (1995) indicated that the discharge coefficient of duckbill weirs is reduced by increasing the $\mathrm{H}_{\mathrm{t}} / \mathrm{P}$ ratio. Cassidy (1970) and Lux (1984) used hydraulic models and total head water instead of piezometric head and computed the required parameters, obtained empirical relations for the discharge over the duckbill weirs. Ghodsian (2009) obtained the headdischarge relation empirically, for duckbill weirs with different crest shapes. He found out that the discharge coefficient depends on the ratio of the weir length to its width and the ratio of total head to the weir height and the shape of weir crest. Crookston and Tullis (2013) presented a method for hydraulic design and the analysis for duckbill weirs based on physical models. Heidarpour et al. (2006) studied the discharge coefficient situation in duckbill weirs with one cycle that showed in rectangular and U-shape form in the plan view. Carollo et al. (2012) used dimensional analysis to investigate the effective factors on the flow from the sharp-edge duckbill weirs. By analyzing the duckbill weirs, Parvaneh et al. (2010) found out that the flow lines are relatively perpendicular to the weir crest until the time that the flow depth of the weir is low and all the length of the crest is used effectively, such that by increasing the flow depth, the perpendicularity is reduced and the flow lines are deviated from the normal state; thus, the effective length of the crest is reduced. Kabiri-Samani (2010) analyzed the effect of using the guide vanes on oblique weirs and found that using guide vanes in perpendicular state relative to the weir can increase the discharge coefficient by $33 \%$. The purpose of this study was to investigate the effect of flow guide vanes on increasing the performance of triangular duckbill weir. Triangular duckbill weir, due to an increase in the effective length of the crest, have a higher flow discharge in the lower water head than straight weir. Thus triangular duckbill weir have better hydraulic performance than straight weir. In this study, hydraulic performance has been investigated. The flow coefficient parameter has been calculated and used as a factor affecting hydraulic performance.

Since no particular studies are published so far about the application of guide vanes in the upstream of the duckbill weirs in straight channels, the guide vanes that are installed in floating position in the upstream of the triangular duckbill weir with $45^{\circ}$ and $90^{\circ}$ vertex angles are used. The aim for that is conducting the flow in high discharge rates in the Perpendicular direction to the triangular duckbill weir wall and also evaluating its effects on the discharge coefficient of the triangular duckbill weir.

\section{Materials and Methods}

This research was done in the hydraulic laboratory of Agriculture Faculty/Isfahan University of Technology. The considered laboratory channel has the dimensions with the length of $7 \mathrm{~m}$, width of $0.32 \mathrm{~m}$ and height of $0.36 \mathrm{~m}$. The wall and the floor of the channel are made of plexiglass with the thickness of $10 \mathrm{~mm}$. This channel is fed by two parallel pumps with maximum flow discharge of $20 \mathrm{lit} / \mathrm{sec}$. The considered models are two triangular duckbill weirs with $45^{\circ}$ and $90^{\circ}$ vertex angles of galvanized sheet with $1 \mathrm{~mm}$ thickness and the threshold of flat edge weir. The height of these models, with regards to the suggested relation by the previous researchers, i.e., $W / P \geq 2.5$ (where $P$ is the weir height and $\mathrm{W}$ is the channel width), is considered equal to $12 \mathrm{~cm}$. a straight weir with a length of equal to the width of the weirs was tested for calculating the equivalent flow discharge (Fig. 2). The water after passing through the overflow, hits the 
channel wall and interferes with the flow in the downstream overflow and this interference reduces the flow velocity (Hay and Taylor, 1972).

The conditions of the laboratory channel are the same for all models. In these experiments, overflow performance is tested in the presence and absence of guide vanes. In laboratory experiments, should be able to exclude the effect of surface tension on the overflow. That is, the height of water over the overflow should not be less than 3 centimeters. Selecting all flow streams was done with consideration of this issue. The effect of water reversal is not considered for all models.

The guide vanes are considered with galvanized sheet with the thickness of $1 \mathrm{~mm}$ and 4 different widths of $2,3,4$ and $5 \mathrm{~cm},\left(\mathrm{~L}_{\mathrm{V}} / \mathrm{L}=0.024,0.036,0.048,0.06\right.$ respectively). First, the vanes with the heights of higher and lower the weir height were used, but after testing and analyzing the results, it was found that the vanes with the heights of higher than the weir height had negative effect on the hydraulic of the flow. On the other hand, vanes with lower heights than the weir height have no effects on improving the efficiency of the weir. Table 1 indicates different conditions for installing the guide vanes.
Figure 3 to 5 show the placement of the guide vanes in different situations. Figure 6 shows some cases of the weirs under study.

Specifications of the tests in this study are indicated in Table 2.

Since the aim in the tests of Group 1 is analyzing the width of the vanes which is represented by the $\mathrm{LV} / \mathrm{L}$ non-dimensional ratio, the other conditions including the distance of the place of installing the vanes to the weir and the wall angle of located vane should be fixed. Due to experimental conditions, the distance of the vanes from each side is considered $8 \mathrm{~cm}$ in both weirs with $45^{\circ}$ and $90^{\circ}$ vertex angles for all the different 4 cases. Selecting the vane width is based on a percentage of the length of a side of the triangular duckbill weir. The vanes are exactly located in the middle of each side and the wall angle of located vane of the weir is $45^{\circ}$. The weirs are installed at the distance of $4.5 \mathrm{~m}$ from the beginning of the channel. The reason of select this distance is the complete development of the flow at the distances of 3.5 to $4.5 \mathrm{~m}$ of the channel.

Table 1: Grouping the tests performed in this study

\begin{tabular}{|c|c|c|}
\hline Title & Purpose & Specifications of tests \\
\hline Group1 & $\begin{array}{l}\text { Effect of vane width } \\
\text { ratio }\left(L_{V} / L\right)\end{array}$ & $\begin{array}{l}\text { In triangular duckbill weir with } \alpha=45^{\circ} \text { or } 90^{\circ} \text {, the vane width }=2,3,4 \text {, or } 5 \\
\mathrm{~cm}\left(\mathrm{~L}_{\mathrm{V}} / \mathrm{L}=0.024,0.036,0.048,0.06\right) \text { located at the } 8 \mathrm{~cm} \text { from the weir with } \\
\theta=45^{\circ} \text { (Fig. 3). }\end{array}$ \\
\hline Group2 & $\begin{array}{l}\text { Effect of wall angle of } \\
\text { located vane }\end{array}$ & $\begin{array}{l}\text { In triangular duckbill weir with } \alpha=45^{\circ} \text { or } 90^{\circ} \text {, the vane with } \theta=35,45,65 \text {, } \\
\text { or } 90 \text { degree located at the } 8 \mathrm{~cm} \text { from the weir (Fig. } 4 \text { ). }\end{array}$ \\
\hline Group3 & $\begin{array}{l}\text { Effect of distance from } \\
\text { located vane }\end{array}$ & $\begin{array}{l}\text { In triangular duckbill weir with } \alpha=90^{\circ} \text {, the vane width }=4 \mathrm{~cm} \text { located at the } \\
8,22 \text { or } 33 \mathrm{~cm} \text { straight from the center of weir side (Fig. } 5 \text { ) }\end{array}$ \\
\hline
\end{tabular}

Table 2: Specifications of tests in this study

\begin{tabular}{ll}
\hline Parameter & The range of changes \\
\hline $14.05-19.19$ & Q(lit/s) \\
$158-177$ & Upstream water level in triangular duckbill weir with vertex angle $=45^{\circ}(\mathrm{mm})$ \\
$26-44 / 3$ & Average upstream velocity in triangular duckbill weir with vertex angle $=45^{\circ}(\mathrm{cm} / \mathrm{s})$ \\
$176-197$ & Upstream water level in triangular duckbill weir with vertex angle $=90^{\circ}(\mathrm{mm})$ \\
$22.8-30$ & Average upstream velocity in triangular duckbill weir with vertex angle $=90^{\circ}(\mathrm{cm} / \mathrm{s})$ \\
\hline
\end{tabular}

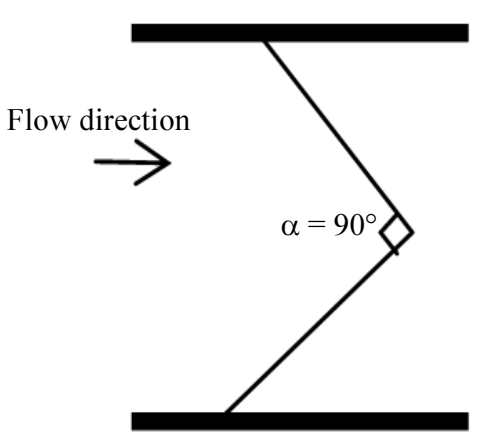

Duckbill weir

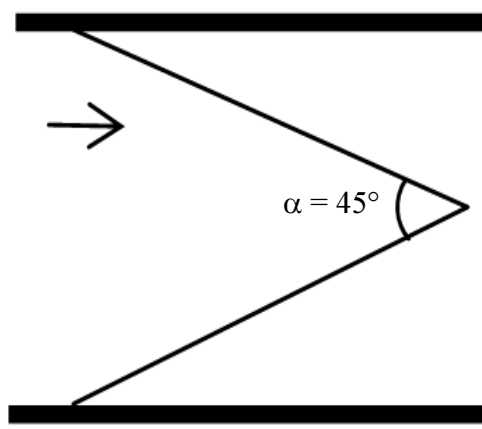

Duckbill weir

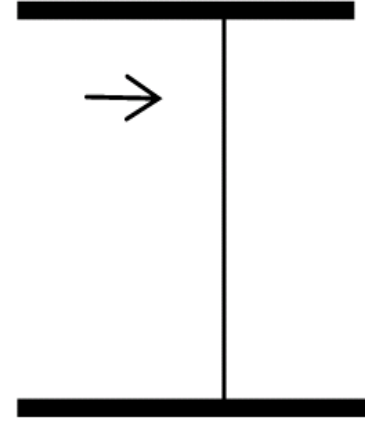

Straight weir

Fig. 2: Sketch of the direct weir and triangular duckbill weirs tested in this study with $\alpha=45^{\circ}$ or $90^{\circ}$ 


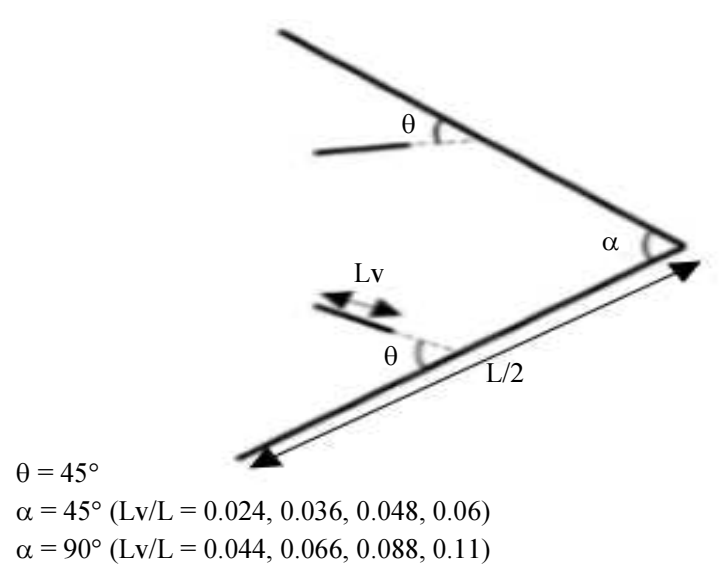

Fig. 3: Positions of vanes in the tests of Group 1

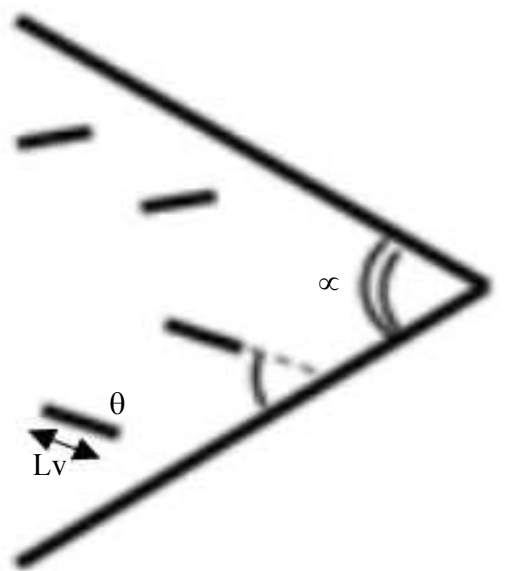

$\theta=35^{\circ}, 45^{\circ}, 65^{\circ}, 90^{\circ}$

$\alpha=45^{\circ}, 90^{\circ}$

$\mathrm{Lv} / \mathrm{L}=0.048$

Fig. 4: Positions of vanes in the tests of Group 2

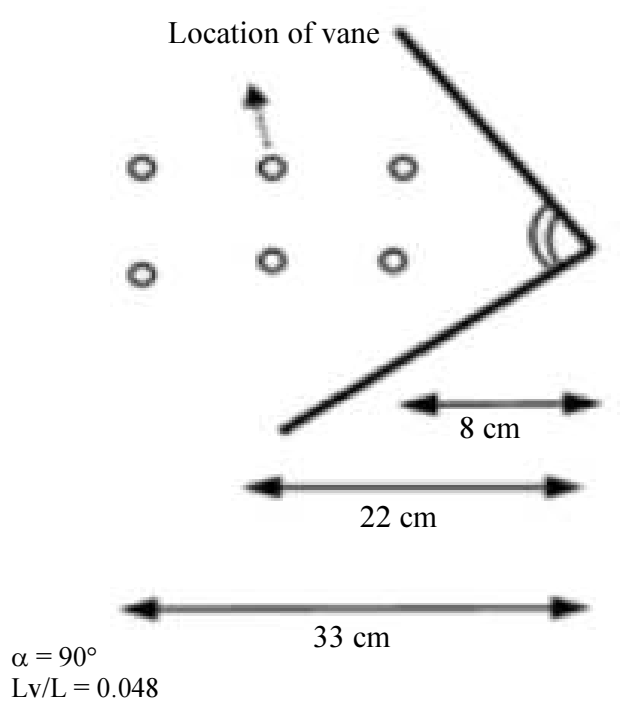

Fig. 5: Positions of vanes in the tests of Group 3 

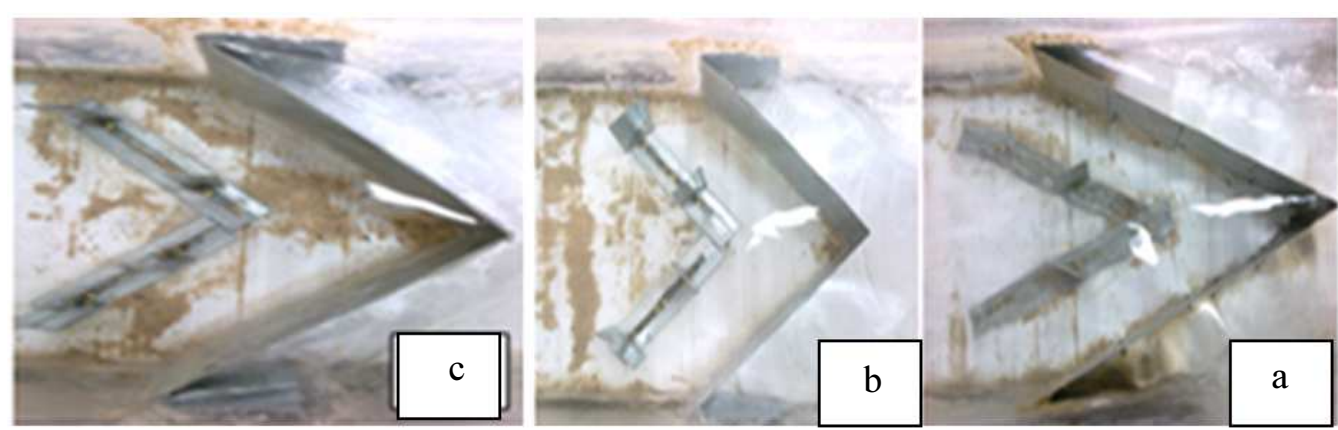

Fig. 6: Examples of tested models, (a). Triangular duckbill weir with $\alpha=45^{\circ}, \theta=45^{\circ}$ and $\mathrm{L}_{\mathrm{V}} / \mathrm{L}=0.048$ in the test of Group1, (b). Triangular duckbill weir with $\alpha=90^{\circ}, \theta=90^{\circ}$ in the test of Group2, (c). Triangular duckbill weir with $\alpha=45^{\circ}, \theta=$ $45^{\circ}$ in the test of Group 2

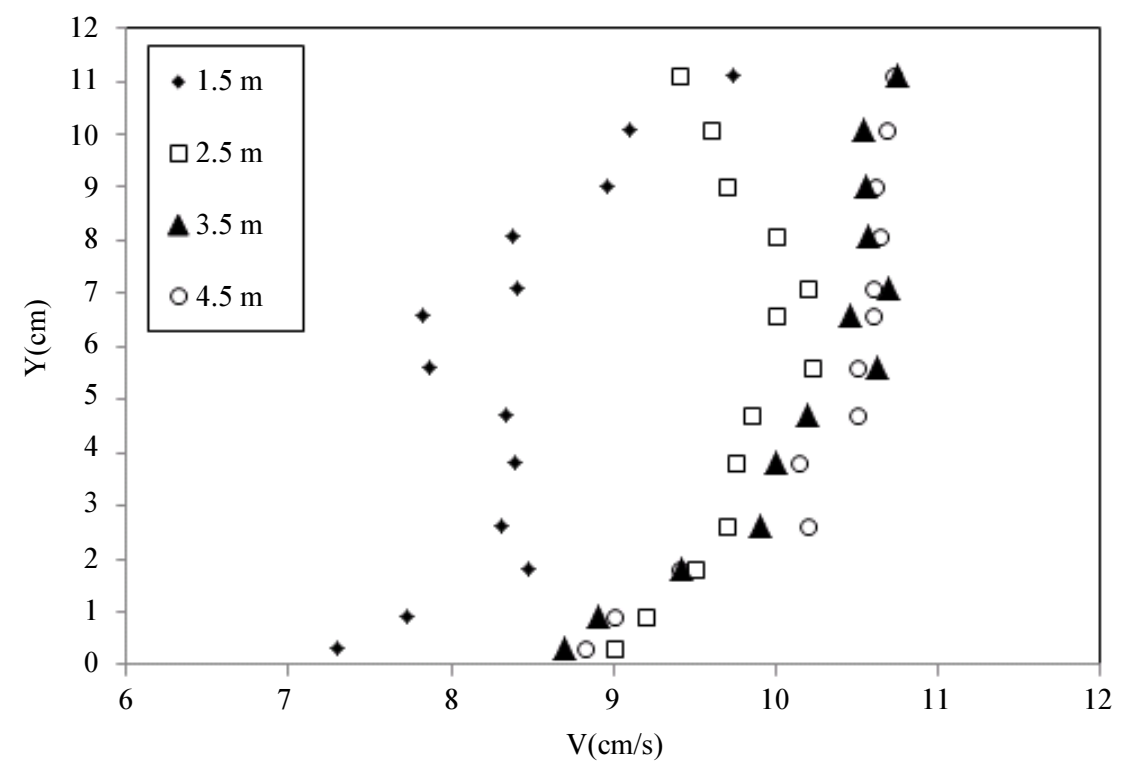

Fig. 7: Velocity profiles at the distances of 1.5, 2.5,3.5 and $4.5 \mathrm{~m}$ at the beginning of the central axis in flow channel

According to Fig. 7, the velocity profiles are coincided on each other at $3.5 \mathrm{~m}$ and $4.5 \mathrm{~m}$ distances. The flow discharge for the study was obtained by Magnetic Flow Meter. Measurement of the water depth at the upstream and on the weir and measuring the longitudinal profile of the water level was done by a depth meter (with the precision of $1 \mathrm{~mm}$ and for max. precision at each reading, the indicating number of the depth meter relative to the channel floor was set to zero). The flow velocity was measured by an Acoustic Doppler velocimeter (this device can calculate the velocity at the distance of $\mathrm{min} .3 \mathrm{~mm}$ from the floor). To help the development of the flow, the distance of $1 \mathrm{~m}$ from the beginning of the channel was covered by gravelling to increase the roughness. After installing the weir in the channel and getting steady flow, the level of the water for free flow conditions was measured. First, the data related to the depth, velocity and flow discharge for the simple triangular duckbill weirs were recorded. After that, the test was done at the presence of flow guide vanes with regards to different cases stated in Table 1 and for different flow discharge for the three types of vanes. Providing the min. condition $3 \mathrm{~cm}$ for head water on the weir is essential in order to ignore the viscosity effects and surface tension. It is to note that the head water is obtained from subtracting the water depth and the weir height. The considered relation for calculating the discharge coefficient is the general relation for the weirs (Equation 1).

\section{Results}

\section{Analysis of Group 1 Tests}

For the Group 1 testing conditions, the graph for the efficiency changes $Q_{L} / Q_{N}$ relative to $H_{t} / P$ (where $H_{t}$ is the total head water including static head and velocity head and $\mathrm{P}$ is the height of the weir) is drawn for the 
weir with the vertex angle of $90^{\circ}$ (Fig. 8). Here, $Q_{L}$ is the triangular duckbill weir flow discharge and $\mathrm{Q}_{\mathrm{N}}$ is the straight weir flow discharge with a length equivalent to the width of the channel and the total hydraulic head is equal to the total hydraulic head of the triangular duckbill weir and $\mathrm{Q}_{\mathrm{N}}$ is obtained from Equation 1, but the discharge coefficient of the straight weir is used in that equation. According to the illustration, existence of the flow guide vanes at the distance of $8 \mathrm{~cm}$ at the upstream has no positive effects on the efficiency of the weir, regarding the weir with the vertex angle of $90^{\circ}$, since the weir efficiency in all the widths is less than that for the simple triangular duckbill weir with the vertex angle of $90^{\circ}$. Figure 8 shows that the change of the weir efficiency with increased $\mathrm{H}_{\mathrm{t}} / \mathrm{P}$ has a reducing trend in all the testing situations including simple triangular duckbill weir and in the presence of flow guide vanes. The general trend of change of $\mathrm{Q}_{\mathrm{L}} / \mathrm{Q}_{\mathrm{N}}$ to $\mathrm{H}_{\mathrm{t}} / \mathrm{P}$, such as research by Parvaneh et al. (2010) with increasing in $\mathrm{H}_{\mathrm{t}} / \mathrm{P}$ is downside.

In the weir with vertex angle $45^{\circ}$, the existence of guide vanes in the upstream of the weir has a positive effect on the weir efficiency. In all $\mathrm{L}_{\mathrm{V}} / \mathrm{L}$, the duckbill weir efficiency is greater than the simple duckbill weir efficiency with vertex angle $45^{\circ}$. Figure 9 shows that
$\mathrm{L}_{\mathrm{V}} / \mathrm{L}=0.024$ and 0.036 have better efficiency than more $\mathrm{L}_{\mathrm{V}} / \mathrm{L}=0.048$ and 0.06 .

\section{Analysis of Group 1 Tests}

Regarding the testing conditions for Group 2, Fig. 11 shows the efficiency changes $\mathrm{Q}_{\mathrm{L}} / \mathrm{Q}_{\mathrm{N}}$ relative to $\mathrm{H}_{\mathrm{t}} / \mathrm{P}$. According to the illustration, existence of flow guide vanes in the distance of $8 \mathrm{~cm}$ in all the angles including $35,45,65$ and $90^{\circ}$ causes reduction in the efficiency of the weir, when its vertex angle is $90^{\circ}$.

However, regarding the $45^{\circ}$ weirs, the guide vanes have positive effect on the weir efficiency. It can be seen in Fig. 12 and 13 that the wall angle of located vane $35^{\circ}$ and $45^{\circ}$ increase the efficiency. By increasing the $\mathrm{H}_{t} / \mathrm{P}$, the effects of vanes in these two angles are more in increasing the weir efficiency, while the effects are negative for the wall angles of $65^{\circ}$ and $90^{\circ}$. The reason for that can be explained that since by increasing the flow discharge in triangular duckbill weirs with low vertex angle, the curvature of the flow in normal direction to the weir is increased, these vanes in appropriate distances from each other and from the weir can cause the flow conduction in the vertical direction to the weir and the horizontal component of the velocity is inclined to zero.

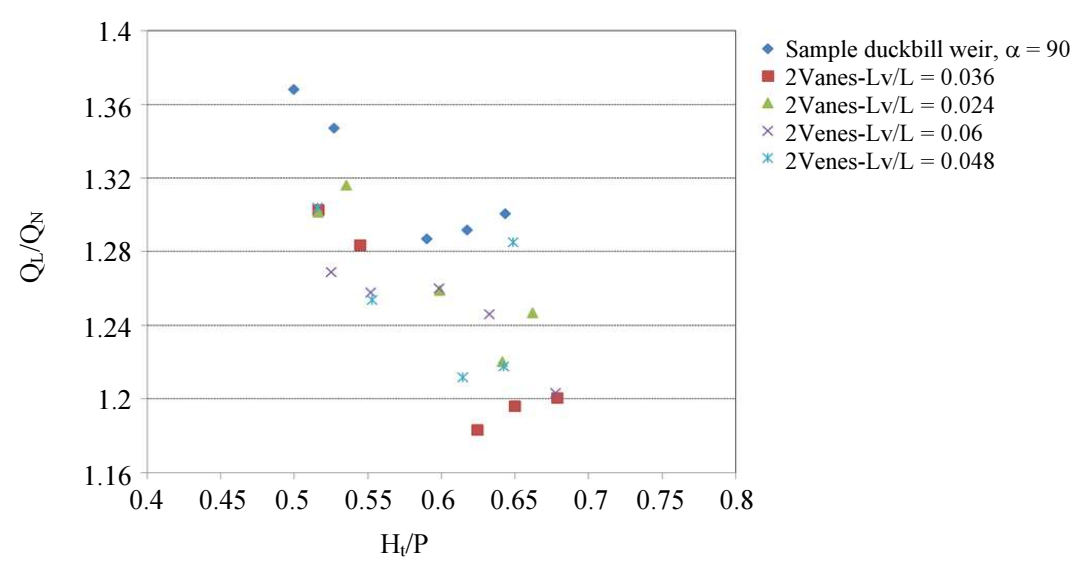

Fig. 8: Variations of weir efficiency $\left(\mathrm{Q}_{\mathrm{L}} / \mathrm{Q}_{\mathrm{N}}\right)$ relative to $\mathrm{Ht} / \mathrm{P}$ in experiments of group 1 in duckbill weir with $\alpha=90^{\circ}$

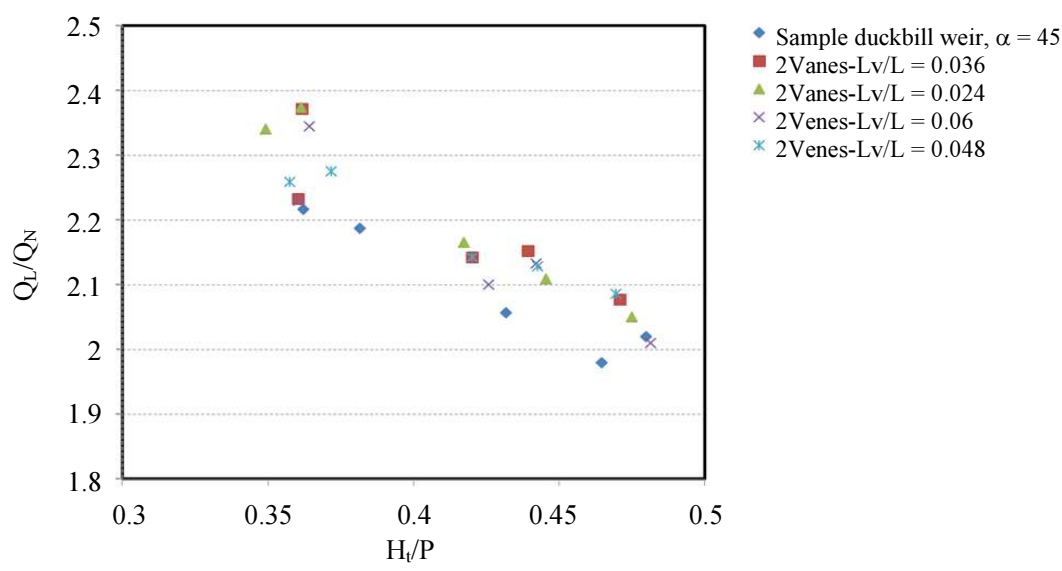

Fig. 9: Variations of weir efficiency $\left(\mathrm{Q}_{\mathrm{L}} / \mathrm{Q}_{\mathrm{N}}\right)$ relative to $\mathrm{Ht} / \mathrm{P}$ in experiments of group 1 in duckbill weir with $\alpha=45^{\circ}$ 


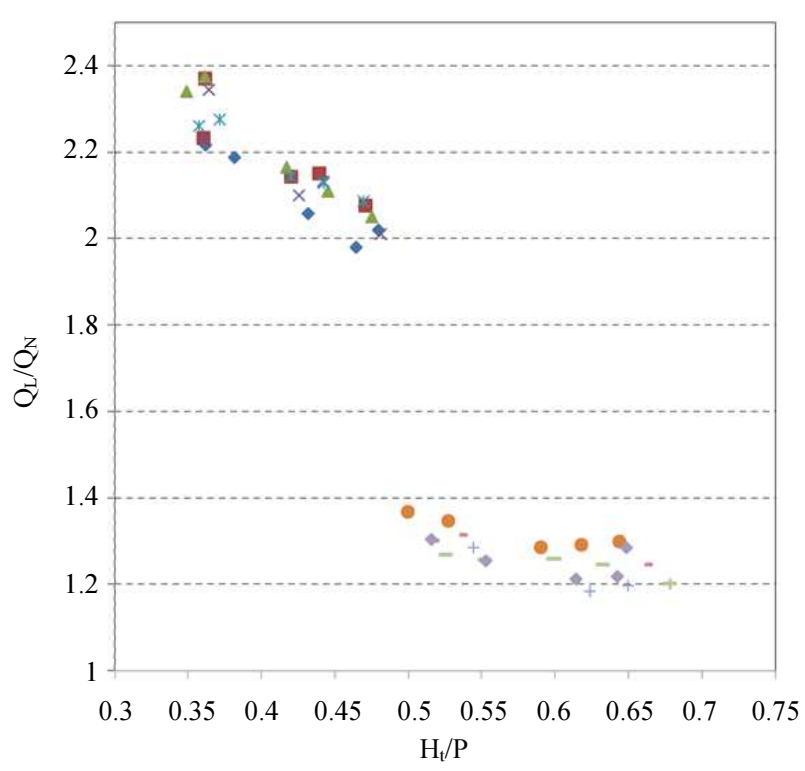

- Sample duckbill weir, $\alpha=45$

⿶2Vanes-Lv/L $=0.036, \alpha=45$

$\triangle 2$ Vanes-Lv $/ \mathrm{L}=0.024, \alpha=45$

$\times 2$ Venes-Lv $/ \mathrm{L}=0.06, \alpha=45$

*2Venes-Lv/L $=0.048, \alpha=45$

- Sample duckbill weir, $\alpha=90$

+2 Vanes- $\mathrm{Lv} / \mathrm{L}=0.036, \alpha=90$

-2Vanes-Lv/L $=0.024, \alpha=90$

-2 Venes-Lv/L $=0.06, \alpha=90$

- 2 Venes-Lv $/ \mathrm{L}=0.048, \alpha=90$

Fig. 10: Comparison between weir efficiency variations $\left(\mathrm{Q}_{\mathrm{L}} / \mathrm{Q}_{\mathrm{N}}\right)$ relative to $\mathrm{Ht} / \mathrm{P}$ in experiments of group 1 in duckbill weir with $\alpha=$ $45^{\circ}$ and $\alpha=90^{\circ}$



* Sample duckbill weir, $\alpha=90$

- $\theta=90$

$\triangle \theta=45$

- $\theta=35$

$\wedge=65$

Fig. 11: Variations of weir efficiency $\left(\mathrm{Q}_{\mathrm{L}} / \mathrm{Q}_{\mathrm{N}}\right)$ relative to $\mathrm{Ht} / \mathrm{P}$ in experiments of group 2 in duckbill weir with $\alpha=90^{\circ}$

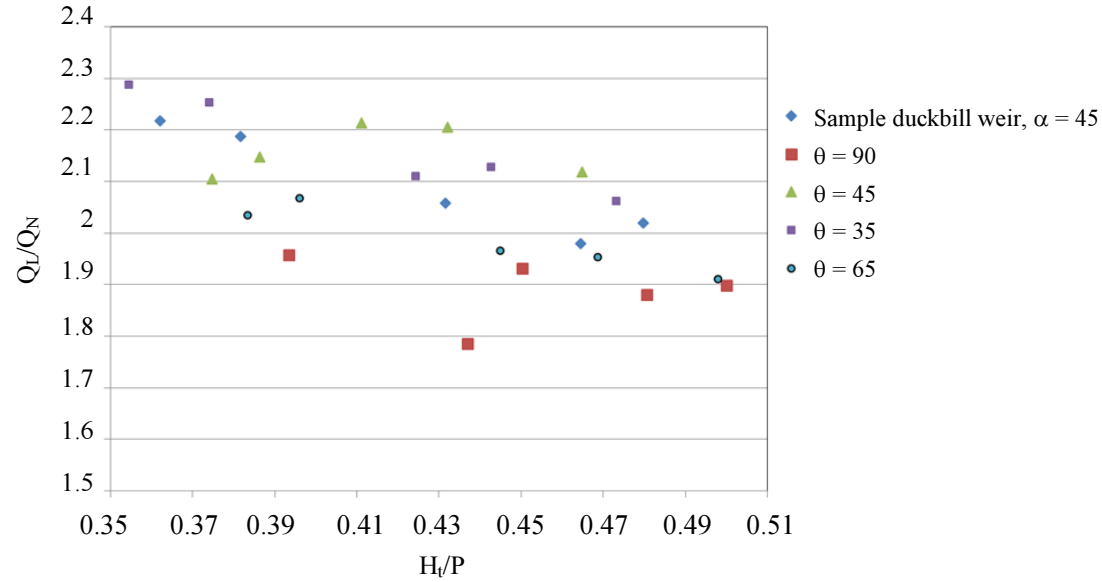

Fig. 12: Variations of weir efficiency $\left(\mathrm{Q}_{\mathrm{L}} / \mathrm{Q}_{\mathrm{N}}\right)$ relative to $\mathrm{Ht} / \mathrm{P}$ in experiments of group 2 in duckbill weir with $\alpha=45^{\circ}$ 


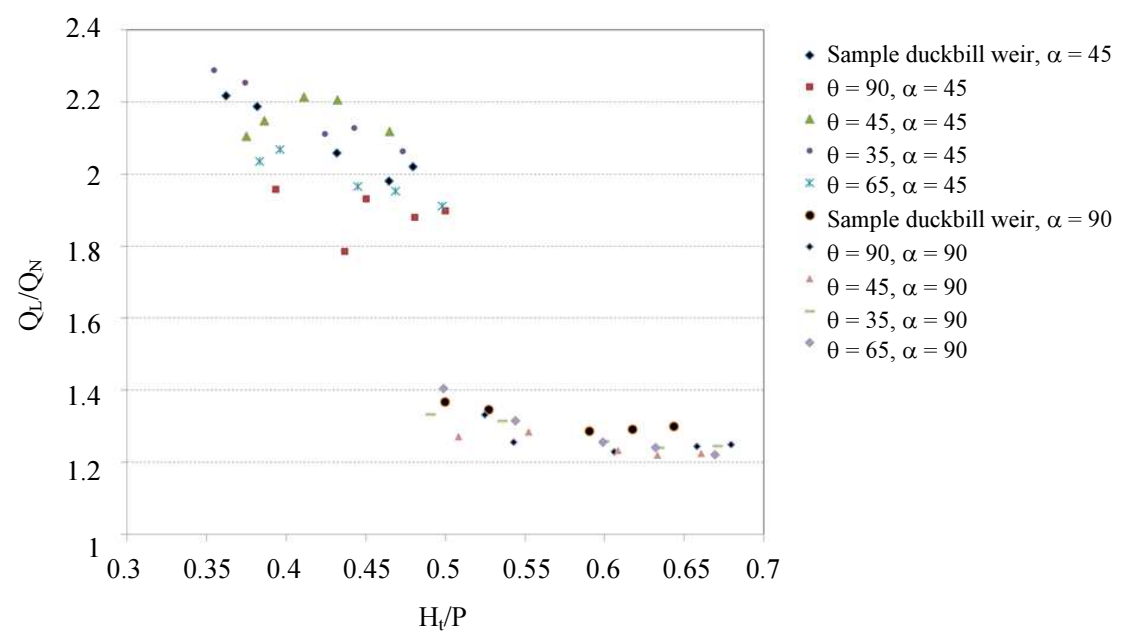

Fig. 13: Comparison between weir efficiency variations $\left(\mathrm{Q}_{\mathrm{L}} / \mathrm{Q}_{\mathrm{N}}\right)$ relative to $\mathrm{Ht} / \mathrm{P}$ in experiments of group 2 in duckbill weir with $\alpha=$ $45^{\circ}$ and $\alpha=90^{\circ}$

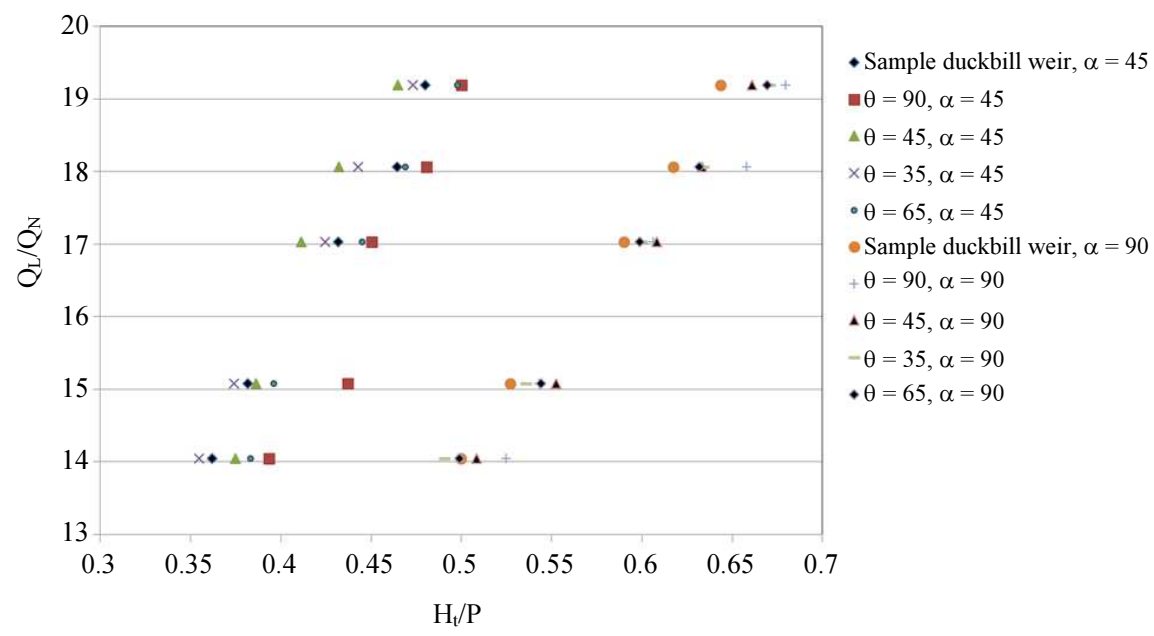

Fig. 14: Comparison between flow discharge variations relative to Ht/P in experiments of group 2 in duckbill weir with $\alpha=45^{\circ}$ and $\alpha=90^{\circ}$

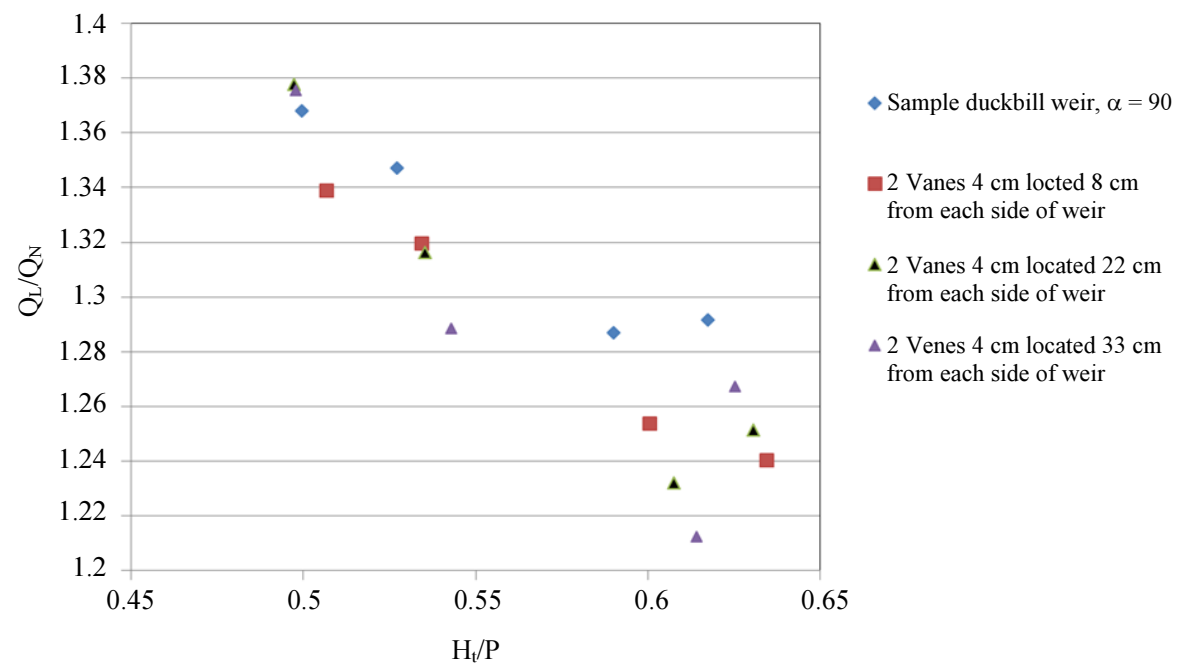

Fig. 15: Variations of weir efficiency $\left(\mathrm{Q}_{\mathrm{L}} / \mathrm{Q}_{\mathrm{N}}\right)$ relative to $\mathrm{Ht} / \mathrm{P}$ in experiments of group 3 


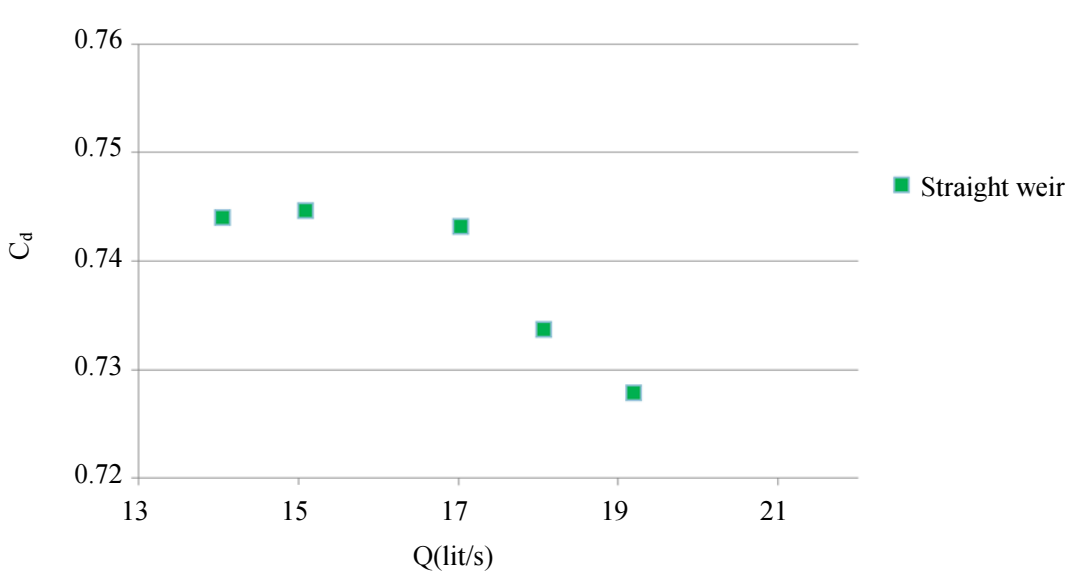

Fig. 16: Variations of weir coefficient $\left(C_{d}\right)$ relative to $Q($ lit/s) in straight weir

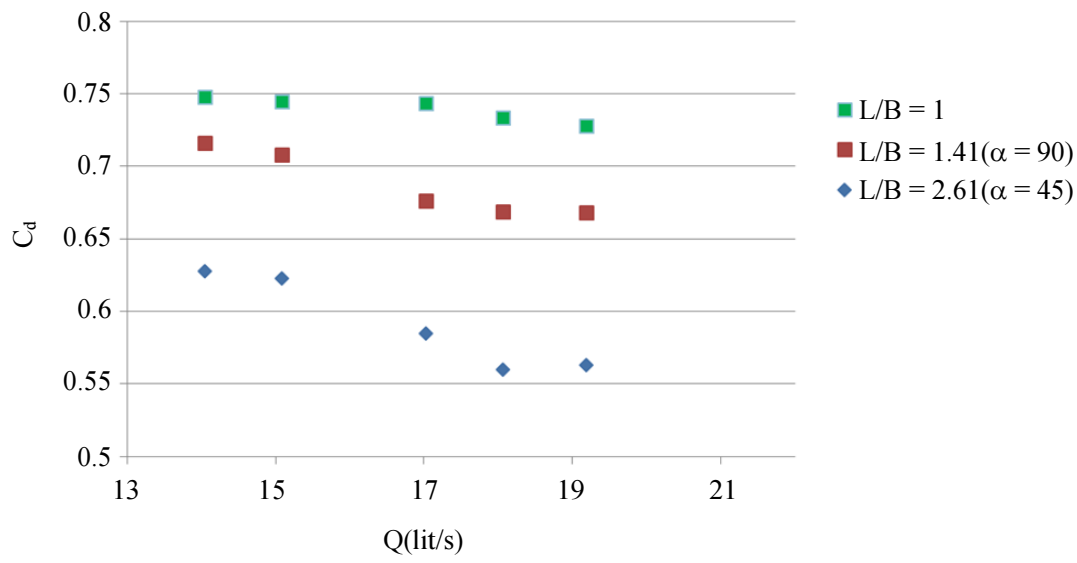

Fig. 17: Variations of weir coefficient $\left(C_{d}\right)$ relative to $Q$ (lit/s) in straight weir ( $\left./ B=1\right)$, Duckbill weir with $\alpha=90^{\circ}(\mathrm{L} / \mathrm{B}=1.41), \alpha$ $=90^{\circ}(\mathrm{L} / \mathrm{B}=2.61)$

Hence, the vertical component of the velocity to the weir is maximized and the flow is passing over the weir as in straight weirs. Thus, the flow discharge is increased. But, in larger vertex angles, the effect of vanes on providing the flow in normal direction is not much, since the flow curvature is not much. In this case, In this case, the vanes are placed in an obstacle to the flow, causing to rises the upstream water level and to reduce the flow velocity, leading to reduction in the flow discharge in duckbill weir compared to simple duckbill weir.

By comparing the curves, it is clear that the highest efficiency in the group of weirs with vertex angle $45^{\circ}$ is related to the vanes with the wall angle of $35^{\circ}$ and that in the group of weirs with vertex angle $90^{\circ}$ is related to the vanes with the wall angle of $35^{\circ}$.

Figure 14 also shows the increasing flow discharge in the weirs with vertex angle of $45^{\circ}$ in comparison to that with the vertex angle of $90^{\circ}$. According to the illustration, it can be seen that all the tested models of weir with vertex angle $90^{\circ}$ require a higher rate of $\mathrm{H}_{\mathrm{t}} / \mathrm{P}$ for similar flow discharge to the weirs with vertex angle $45^{\circ}$, which indicates lower efficiency of this type of weir as compared to the weirs with vertex angle $45^{\circ}$.

Regarding the testing conditions for Group 3, Fig. 15 shows the efficiency changes $Q_{L} / Q_{N}$ relative to $H_{t} / P$. According to the illustration, existence of flow guide vanes in the distances of 8,22 and $33 \mathrm{~cm}$ in the weir with vertex angle of $90^{\circ}$ have no positive effects on the weir efficiency and the efficiency is reduced in all the different cases. It can be seen from Fig. 15 that by increasing the vane distances, the efficiency faces more reduction, indicating that for the weirs with the vertex angle of $90^{\circ}$ in high flow discharge, the flow intervention is not so much to require flow guide vanes, since it was found that the efficiency is decreased by using the vanes.

In Fig. 16, the values of the flow coefficient with flow change are shown over the straight weir. To calculate the discharge coefficient of the straight weir, the tests for the straight weir for similar flow discharge of the triangular duckbill weir are repeated. 


\section{Discussion}

In a general comparison between weirs with $45^{\circ}$ and $90^{\circ}$ vertex angle and according to Fig. 10 , it is clear that in all the different cases for tests of Group 1 , the $45^{\circ}$ weir efficiency is better than that for the $90^{\circ}$ weir. In the tests, it was founded out more efficiency in lower head water for the weir with vertex angle $45^{\circ}$ as compared to the weir with vertex angle $90^{\circ}$. By increasing the flow discharge regarding the triangular duckbill weirs with low vertex angle, the flow curvature from the perpendicular is high, the existence of the guide vanes can conduct the flow in the vertical direction to the weir and the horizontal component of velocity approaches to zero. Therefore, the vertical component of velocity over the weir was maximized and this flow was similar to the flow over the straight weir. Thus, the weir efficiency is increased. Comparison of the curves shows that maximum efficiency in the Group of weirs with vertex angle $45^{\circ}$ is related to the $\mathrm{LV} / \mathrm{L}=0.024$ and in the Group of weirs with vertex angle $90^{\circ}$ is related to the simple weir with no vanes.

Finally, the L/B parameter, in which $\mathrm{L}$ is the effective length of the flow and B is the channel's width, is important for duckbill weir. In the case of the weirs used in this study, for the vertex angle of $90^{\circ}$, the value $\mathrm{L} / \mathrm{B}=1.41$ and for the vertex angle of $45^{\circ}$, the value $\mathrm{L} / \mathrm{B}=2.61$. With reference to Fig. 17, the general trend of discharge coefficient changes decreases with increasing discharge. Also, increasing the vertex angle of the duckbill weir decreases the discharge coefficient. Duckbill weir discharge coefficient is obtained in both cases less than straight weir. The trend of changes in the discharge coefficient corresponds to the consequences of research by Tullis et al. (1995).

\section{Conclusion}

- Results showed that by increasing $\mathrm{H}_{\mathrm{t}} / \mathrm{P}$, the efficiency of triangular duckbill weirs is reduced in all the different cases and it is in conformity with the results obtained by Hay and Taylor (1970) and Tullis et al. (1995)

- Using flow guide vanes in triangular duckbill weirs with vertex angle $45^{\circ}$ is effective, while no positive effects can be observed in weirs with vertex angle $90^{\circ}$, sometimes having negative effects in increasing the efficiency

- Improving the weir efficiency in lower $\mathrm{Ht} / \mathrm{P}$ is more in triangular duckbill weirs with vertex angle $45^{\circ}$

- In triangular duckbill weirs with low vertex angle and using flow guide vanes, the horizontal component of the flow velocity over the weir approached near zero and the vertical component of the flow velocity is magnified. Thus, at that time, the flow goes over the weir crest with higher velocity and therefore, the flow discharge is increases and the discharge coefficient is also increased for the equivalent head water. In other words, the flow for the triangular duckbill weir will be similar to that for the straight weirs

\section{Acknowledgment}

In the end, thanks and gratitude to all the colleagues and professors who co-operated with this research.

\section{Author's Contributions}

Sayedeh Zahra Hosseini-Teshnizi, Manuchehr Heidarpour and Saeid Eslamian: Write manuscript.

Vijay P. Singh, Sayedeh Zahra Hosseini-Teshnizi and Kaveh Ostad-Ali-Askari: Write manuscript and revise it.

\section{Ethics}

In this article, all ethical principles related to scientificresearch articles such as: validity and authenticity, originality, data collection in a standard manner, integrity and accuracy of research and ... are observed.

\section{References}

Abrishami, J. and S.M. Hosseini, 1993. Open Channel Hydraulics. 1st Edn., Elsevier, Amsterdam, Boston, ISBN-10: 0080479804, pp: 384.

Carollo, F., V. Ferro and V. Pampalone, 2012. Experimental investigation of the outflow process over a triangular labyrinth-weir. J. Irrigat. Drainage Eng., 138: 73-79. DOI: 10.1061/(ASCE)IR.1943-4774.0000366

Cassidy, J.J., 1970. Designing spillway crests for highhead operation. J. Hydraulic Eng., 96: 745-753.

Crookston, B. and B. Tullis, 2013. Hydraulic design and analysis of labyrinth weirs. I: Discharge relationships. J. Irrigat. Drainage Eng., 139: 363-370. DOI: 10.1061/(ASCE)IR.1943-4774.0000558

Ghodsian, M., 2009. Stage-discharge relationship for a triangular labyrinth spillway. J. Water Manage., 162: 173-178. DOI: 10.1680/wama.2009.00033

Hay, N. and G. Taylor, 1970. Performance and design of labyrinth weir. J. Hydraulic Eng., 96: 2337-2357.

Hay, N. and G. Taylor, 1972. Performance and design of labyrinth weirs. J. Hydraulic Eng., 96: 708-711.

Heidarpour, M., S.F. Mousavi and A.R. Roushani Zarmehri, 2006. Investigation of rectangular and ushaped labyrinth weirs. JWSS, 10: 1-12.

Kabiri-Samani, A.R., 2010. Analytical approach for flow over an oblique weir. J. Civil Eng., 17: 107-117. 
Lux, F., 1984. Discharge characteristics of labyrinth weirs. Proceeding of the International Conference on Water for Resource Development, (WRD' 10), American Society of Civil Engineering, Coeur d'Alene, Idaho.

Parvaneh, A., S.M. Borghei and M.R. Jalili-Ghazizadeh, 2010. Discussion of "Discharge capacity of labyrinth side weir located on a straight channel" by M. Emin Emiroglu, Nihat Kaya and Hayrullah Agaccioglu. J. Irrigat. Drainage Eng., 137: 743-745. DOI: 10.1061/(ASCE)IR.1943-4774.0000272

Tullis, J.P., N. Amanian and D. Waldron, 1995. Design of labyrinth spillways. J. Hydraulic Eng., 121: 247-255. DOI: 10.1061/(ASCE)0733-9429(1995)121:3(247)

\section{Nomenclauture}

$C_{\mathrm{d}} \quad$ Discharge coefficient (-)

$G \quad$ Gravitational acceleration $\left(\mathrm{m} / \mathrm{s}^{2}\right)$

$H_{t} \quad$ Total head water (m)

$L \quad$ Effective length of the weir (m)

$L_{V} \quad$ Vane width (m)

$L_{V} / L \quad$ Vane width ratio (-)

$P \quad$ Weir height (m)

$Q \quad$ Flow discharge $\left(\mathrm{m}^{3} / \mathrm{s}\right)$

$Q_{L} \quad$ Triangular duckbill weir flow discharge $\left(\mathrm{m}^{3} / \mathrm{s}\right)$

$Q_{N} \quad$ Straight weir flow discharge $\left(\mathrm{m}^{3} / \mathrm{s}\right)$

$V \quad$ Average upstream velocity $(\mathrm{m} / \mathrm{s})$

$W \quad$ Channel width (m)

$\alpha \quad$ Vertex angle (degree)

$\theta \quad$ Wall angle of located vane (degree) 